Revista lus et Praxis, Año 25, № 3, 2019, pp. 409 - 424

ISSN 0717 - 2877

Universidad de Talca - Facultad de Ciencias Jurídicas y Sociales

Los instrumentos de planificación territorial como mecanismo adecuado para

proteger el derecho humano de los indígenas al territorio

Cristóbal Balbontin-Gallo

Trabajo recibido el 23 de octubre de 2018 y aprobado el 29 de agosto de 2019

\title{
Los instrumentos de planificación territorial como mecanismo adecuado para proteger el derecho humano de los indígenas al territorio
}

\section{THE INSTRUMENTS OF TERRITORIAL PLANNING AS AN ADEQUATE MECHANISM TO PROTECT THE HUMAN RIGHT OF INDIGENOUS PEOPLE TO TERRITORY}

\section{Cristóbal Balbontin-Gallo*}

\begin{abstract}
RESUMEN
El conflicto que se perpetúa entre el Estado chileno y el pueblo mapuche es el síntoma de una falta de marco teórico adecuado para abordarlo. En efecto, el Estado se ha concentrado en una lectura económica del conflicto al apoyarse en el Fondo de Tierras y Aguas como mecanismo de redistribución, sin advertir que este conflicto social también puede ser comprendido a partir de una experiencia de agravio que busca -a través de una lucha por el reconocimiento- la restauración moral de una dignidad mancillada. En este sentido sobresale la demanda de los mapuches por el reconocimiento del valor cultural de su relación con el territorio que los rodea. No obstante, al revisar el ordenamiento jurídico nacional es posible advertir que este valor simbólico del territorio para los indígenas no está adecuadamente cautelado, lo que explica en buena medida que surjan conflictos a partir de un uso y explotación poco sustentable de los recursos naturales. Nuestra hipótesis es que, considerando que la explotación de los recursos naturales pasa tanto por el régimen de concesiones de bienes de dominio público como por permisos sectoriales, estimamos que es posible avanzar en la protección del territorio cultural indígena a través de los actuales instrumentos de planificación territorial.
\end{abstract}

\section{ABSTRACT}

The conflict that is perpetuated between the Chilean State and the Mapuche people is the symptom of a lack of adequate theoretical framework to address the conflict. In effect, the State has focused on an economic reading of the conflict by relying on the Land and Water Fund as a mechanism of redistribution, without noticing that this social conflict can also be understood from an experience of grievance that seeks - through of a struggle for recognition - the moral restoration of a tainted dignity. In this regard, the demand of the Mapuche for the recognition of the cultural value of their relationship with the territory that surrounds them stands out. However, when reviewing the national legal system it is possible to notice that this symbolic value of the territory for the indigenous people is not properly guarded, which explains to a large extent that conflicts arise from unsustainable use and exploitation of natural resources. Our hypothesis is that, considering

\footnotetext{
* Doctor en Filosofía por la Universität J. W. Goethe Frankfurt am Main y Université Paris-Nanterre, investigador asociado de IREPH Université Paris-Nanterre, profesor auxiliar de la Universidad Austral, Helena Haverbeck s/n, Campus Isla Teja, Valdivia, Chile. Email: cbalbonting@gmail.com. El presente artículo forma parte del Fondecyt $\mathrm{N}^{\circ} 11190725$, del cual el autor es investigador responsable.
} 
that the exploitation of natural resources goes through the regime of concessions of public domain goods as per sectoral permits, we believe that it is possible to advance in the protection of the indigenous cultural territory through the territorial planning.

\section{Palabras Claves}

Conflicto mapuche, derecho al territorio, recursos naturales.

\section{KEYWORDS}

Mapuche conflict, right to territory, natural resources

\section{Introducción}

El conflicto que se prolonga entre el Estado y el pueblo mapuche es un síntoma de la insuficiencia de las políticas públicas elaboradas con relación a este pueblo indígena. La violencia en las regiones de La Araucanía y de Los Ríos da cuenta de una cierta incapacidad histórica para superar una violencia fundacional que surge con la guerra de Arauco y que se proyecta hasta nuestros días ${ }^{1}$. Lo anterior requiere -en consecuencia- una reflexión detenida que ofrezca una nueva clave de lectura teórica de este conflicto, que permita al Estado avanzar en una vía de solución pacífica y legítima al problema que actualmente concentra una parte importante del conflicto: el uso y explotación de los recursos naturales.

En efecto, si bien al momento de la independencia la construcción del imaginario patriótico se alimenta del mito indómito y "valeroso de la sangre araucana", ${ }^{2}$ rápidamente se impone una política de asimilación cultural que se implementa -sobre todo- a través de la desposesión de las tierras de los indígenas. ${ }^{3}$ Desde el año 1852, con la ley que crea la provincia de Arauco y que incluye los territorios indígenas, pasando por las primeras leyes de ocupación que contemplaron la radicación de los indígenas, se siguió con la usurpación de tierras a través de inscripciones fraudulentas. Por su parte, la Ley $N^{\circ} 4.802$ - que estableció un mecanismo para dividir las comunidades indígenas con el fin de incorporar a los indígenas en el sistema de propiedad individual y a la libre circulación de los bienes hasta la dictación del Decreto Ley № 2.568 de 1979- contempló la posibilidad de que cualquier ocupante de una reserva, indígena o no indígena, solicitara la división de las tierras de una reducción a través de un procedimiento legal expedito, lo que no sólo permitió la asignación de hijuelas de propiedad privada individual a quienes habitaban en ellas, sino además su desafección de la condición indígena. Es a partir de lo anterior que

\footnotetext{
1 Confróntese con Villegas (2008). Asimismo, ONU (2009).

2 Bengoa (2000), p. 28.

3 PINTO (2000), p. 131.
} 
la historiografía ha destacado el elemento "tierra" como el resorte principal de un cierto abuso histórico.

Ello se refleja consecuentemente en la dictación de la Ley $N^{0} 19.253$, sobre Protección, Fomento y Desarrollo Indígena, que contempla la creación del Fondo de Tierras y Aguas Indígenas. Dicho fondo tiene como función principal "solucionar los problemas de tierras, en especial, con motivo del cumplimiento de resoluciones o transacciones judiciales o extrajudiciales, relativas a tierras indígenas en que existan soluciones sobre tierras indígenas o transferidas a los indígenas, provenientes de los títulos de merced o reconocidos por títulos de comisario u otras cesiones o asignaciones hechas por el Estado a favor de los indígenas" (Artículo 20 letra b). Es precisamente este fondo -junto a la asistencia preferente de los servicios públicos en la zona- el que se ha transformado en la práctica en el dispositivo fundamental por parte del Estado en torno al cual se ha organizado, sin éxito, su estrategia para enfrentar los conflictos surgidos de las demandas de las comunidades mapuches. Los recientes acontecimientos de contenido simbólico, asociados a la quema de iglesias, son el síntoma de un malestar que no está adecuadamente comprendido al interior de una concepción de justicia implícita a la Ley Indígena que se reduce a una clave económica de lectura y solución de los conflictos sociales y que entiende, por una parte, que el conflicto mapuche obedece a un problema de pobreza y, por otra parte, a un problema de una injusticia histórica ocasionado por la usurpación ilegítima de tierras.

Desde Aristóteles a Dworkin ha dominado una concepción de justicia social que entiende -en lo fundamental- que los conflictos sociales están motivados por demandas en torno a una correcta distribución de bienes y servicios; en síntesis, los sectores sociales se movilizan para exigir que la riqueza se distribuya en otros términos. Sin embargo, en el caso del pueblo mapuche sobresale adicionalmente la experiencia histórica de agravio, humillación y menosprecio que moviliza a los indígenas a entrar en un conflicto que busca el reconocimiento del valor de su cultura como digna de respeto y consideración, como vía para alcanzar la afirmación de una identidad colectiva digna y segura frente al resto de la sociedad ${ }^{4}$.

Esta insuficiencia del marco teórico resulta especialmente evidente en los conflictos asociados a la explotación de los recursos naturales. En efecto, la ley № 19.253 -Ley Indígena- avanza en una lógica patrimonial de estatuir derechos de dominio en favor de los indígenas sobre la tierra y el agua, en circunstancias

\footnotetext{
${ }^{4}$ En una aplicación concreta de la teoría del reconocimiento de HONNETH (1997). Para una perspectiva crítica de la teoría del reconocimiento y su perspectiva limitada de la importancia de la redistribución para una teoría de la justicia, ver Fraser y HONNETH (2006).
} 
en que el problema también pasa por proteger la relación que el mapuche tiene con su territorio como conjunción de elementos naturales donde esa sociedad encuentra su eficacia cultural. Así, por ejemplo, el pantano para el mapuche es el mallín o lugar del mal, antes que una ciénaga de pasto y agua. Del mismo modo, el valor e identidad de la machi es indisociable del menoko o humedal sagrado que le sirve como reservorio medicinal.

\section{Análisis crítico del valor cultural del territorio cultural indígena en el ordenamiento jurídico nacional}

No obstante, este concepto de territorio no ha sido debidamente recogido por la Ley Indígena ${ }^{5}$. Si bien es cierto que la ley estatuye áreas de desarrollo indígena (art. 26) y que para su establecimiento considera -genéricamente- los espacios territoriales en los que han vivido ancestralmente, lo hace con el fin de focalizar la intervención social del Estado a través de sus planes, políticas y programas, desconociendo su potencial carácter de instrumento de ordenamiento territorial como la aspiración de los indígenas a la reconstitución de sus territorios ${ }^{6}$. Asimismo, si bien la ley contempla un fondo de financiamiento para consolidar derechos de agua y concesiones sobre recursos naturales de acuicultura y pesca, lo hace en una lógica basada enteramente sobre el régimen de propiedad. De este modo, la relación de los indígenas con el territorio y los recursos naturales sigue remitiendo enteramente a la respectiva legislación sectorial ${ }^{7}$.

Ahora bien, al examinar la legislación sectorial referida a los recursos naturales más significativos en el conflicto mapuche -aguas, bosques y borde costero-, la noción de territorio como espacio simbólico sujeto a protección está enteramente ausente.

En efecto, en materia de bosques, la Ley de Bosques (D.S. No 4.363 de 1931) y la Ley $N^{\circ} 20.283$, de Bosque Nativo, no contienen ninguna referencia al bosque como espacio cultural significante para los indígenas. De este modo, los planes de manejo -que aprueban la extracción de árboles- se sancionan en función de criterios de economía agria y preservación biológica de los ecosistemas. Por otra parte, y más allá de la posibilidad excepcional de declarar un bosque monumento nacional, reserva forestal o parque nacional, las prohibiciones de extracción se refieren a la vegetación a ciertas distancias de cursos y fuentes de agua, en pendientes superiores a $45^{\circ}$ y a una distancia de 500 metros de glaciares. Además de lo anterior, la Ley № 18.378 contempla sólo áreas de

\footnotetext{
5 Artwin et al. (2013).

6 Rubilar (2014).

7 Aytwin et al. (2013), p. 184.
} 
protección turística y distritos de conservación de suelos, bosques y agua, sin ninguna referencia a un área de valor indígena. A lo anterior hay que agregar que el ejercicio de potestades públicas por parte de Conaf adolece de un vicio de inconstitucionalidad, ya que las corporaciones y fundaciones de derecho privado no pueden ejercer potestades públicas de acuerdo a los artículos $6^{\circ}$ y $7^{\circ}$ de la Constitución, lo que debilita la fiscalización sobre el destino de los bosques ${ }^{8}$. Más aún, una de las críticas formuladas al actual proyecto de ley que crea el Servicio de Biodiversidad y Áreas Protegidas es justamente que no considera áreas indígenas como zonas de protección ${ }^{9}$. Fruto de ello, en la discusión legislativa se introdujo la propuesta de creación de áreas de conservación indígena que, sin embargo, han sido criticadas por su acento conservacionista, que no considera adecuadamente el uso consuetudinario de los recursos naturales por parte de los indígenas.

Con relación a las aguas, los derechos de los indígenas siguieron siendo regulados por el Código de Aguas de 1981, sin hacer ningún tipo de salvaguarda del agua terrestre, de los cauces fluviales o lacustres como territorio o espacio culturalmente significante para los mapuches. La Ley No 20.027, de 2005, que modificó el Código de Aguas, impuso ciertas regulaciones y restricciones destinadas, por una parte, a corregir algunas distorsiones en el mercado del agua asociadas al acaparamiento y especulación de carácter monopólico y, por otro, destinadas a asegurar un caudal mínimo ecológico con un fin de protección de los ecosistemas ${ }^{10}$. No obstante, tal como lo informa el Banco Mundial, la protección de los intereses de los grupos vulnerables -entre ellos, los mapuches- todavía persiste. Se podría argumentar en contrario que la Ley Indígena contempla un fondo para financiar la adquisición de derechos de agua, a la vez que el artículo 64 de la ley dispone la protección esencial del agua de las comunidades indígenas del norte del país que se encuentran en terrenos de las comunidades como los ríos, canales, acequias y vertientes. No obstante que esta disposición ha permitido la regularización de derechos de indígena sobre

\footnotetext{
${ }^{8}$ Tribunal Constitucional, rol № 379, de 2003, a propósito del control de constitucionalidad del proyecto de ley que creaba el Consejo de la Cultura y las Artes, hoy la referida Ley № 19.891, manifestó que la disposición de dicho texto que facultaba al aludido consejo para integrar y participar de la constitución y financiamiento de una corporación de derecho privado, sin fines de lucro, cuyo objeto principal sería la promoción, fomento y gestión directa de actividades culturales a través de los grupos artísticos estables que dicha norma indicaba, "implicaba autorizarlo para traspasar el ejercicio de funciones que son propias de la Administración del Estado, a entidades de derecho privado como es la corporación a que dicho precepto se refiere, lo que no le está permitido sin alterar la competencia que constitucionalmente le está asignada a los órganos que constituyen la Administración" (considerando septuagésimo cuarto).

9 Liberona (2011).

10 YÁÑez et al. (2011).
} 
el agua, incluso contra propietarios inscritos ${ }^{11}$, ella sigue inserta en un régimen de propiedad privada sobre el agua, a pesar de que los mismos indígenas a la época de la dictación de la Ley Indígena reclamaban una protección sobre el territorio de una forma que hace inseparable la relación de la tierra con el agua, ríos, lagos o zonas marítimas ${ }^{12}$.

No obstante, la Ley No 20.249 de 2008, que crea el Espacio Costero Marino de los Pueblos Originarios, les confiere la administración de este espacio a asociaciones y comunidades que invocan el uso consuetudinario (artículo $6^{\circ}$ ). Sin embargo, existen una serie de dificultades no resueltas en relación con las autoridades que intervienen. En efecto, por una parte, la Comisión de Borde Costero debe aprobar la solicitud de las asociaciones y comunidades, a la vez que es la encargada de delimitar el uso del borde costero. Por otra parte, el espacio costero marino es afectado a destinación por la actual Subsecretaría de Fuerzas Armadas, dependiente del Ministerio de Defensa de conformidad al D.F.L. № 340 de 1960. Además del reparto confuso de competencias y el ejercicio conflictivo de atribuciones, la Ley de Pesca contempla la prioridad de las concesiones marítimas y áreas de manejo preestablecidas, todo lo cual contraviene el sentido mismo que implica reconocer un uso consuetudinario a los indígenas ${ }^{13}$. Por otra parte, no es visible cómo se integra la zonificación del borde costero al bloque de legalidad previsto en el artículo 29 de la Ley General de Urbanismo y Construcciones (LGU) en relación con los demás instrumentos de planificación previstos en el artículo 2.1.1 de la Ordenanza General de Urbanismo y Construcciones (OGUC), a pesar de que el artículo $2^{\circ} \mathrm{N}^{\circ} 57$ de la Ley de Pesca señala expresamente que se trata de un instrumento de planificación territorial de la costa, lo que anticipa la colisión con los otros instrumentos de planificación ${ }^{14}$.

Del mismo modo, la valoración cultural asociada al territorio indígena está protegida por el Decreto $\mathrm{N}^{\circ}$ 40, de 2013, del Ministerio del Medioambiente, que aprueba el Reglamento del Sistema de Evaluación de Impacto Ambiental (SEIA), al señalar que deberá presentar un Estudio de Impacto Ambiental el proyecto que genere efectos adversos significativos sobre "los recursos naturales renovables, incluidos en el suelo, aguas y aire, en lugares con presencia de grupos humanos y pertenecientes a pueblos indígenas" (art. $6^{\circ}$ ), considerando asimismo "la afectación a lugares o sitios en que se lleven a cabo manifestaciones habituales

\footnotetext{
11 Corte Suprema, rol No 986-03, de 22 de marzo de 2004, y Corte Suprema, rol No 2480-08, de 25 de noviembre de 2019.

12 AYLWIN (2000).

13 Hervé (2015).

14 Confróntese con Gissı et al. (2017).
} 
propias de la cultura o folclore de alguna comunidad" (art. 10 letra c). A pesar de que el SEIA busca prevenir conflictos ambientales, la autoridad ambiental ha otorgado la calificación ambiental favorable privilegiando la compensación y mitigación, antes que la estricta protección del medioambiente. El caso más emblemático en este sentido es el proyecto Celulosa Valdivia ${ }^{15}$, en territorio mapuche lafkenche, que demuestra, asimismo, que el control judicial puede ser ineficaz frente al daño del medioambiente. Además, este principio compensatorio ha operado en la práctica como un mecanismo de reasignación de costos de inversión en compensación económica de las comunidades afectadas a través de acuerdos extrajudiciales, lo que ha implicado la captura de estas comunidades, transformando un asunto de interés público en uno de interés privado ${ }^{16}$.

Por su parte, el artículo 13 del Convenio № 169 de la OIT establece que los gobiernos deberán respetar la importancia que para los indígenas revisten los valores espirituales y la cultura en su relación con los territorios. Del mismo modo, el Convenio $N^{\circ} 169$ contempla, en sus artículos $7^{\circ} N^{\circ} 1$ y $6 N^{\circ} 1$ letra a), el derecho de los pueblos indígenas a participar en la formación, aplicación y evaluación de los planes y programas de desarrollo nacional y regional susceptible de afectarlos directamente, así como la obligación de los gobiernos de consultar a los pueblos interesados, mediante procedimientos apropiados, cada vez que se prevean medidas legislativas o administrativas susceptibles de afectarlos directamente ${ }^{17}$. Además, el artículo $4^{\circ}$ de la Ley $N^{0} 19.300$-Ley de Bases Generales de Medioambiente-, modificado por la Ley № 20.417, señala explícitamente que es deber del Estado facilitar la participación ciudadana, mencionando expresamente -en el inciso segundo- "la adecuada conservación, desarrollo y fortalecimiento de la identidad, idiomas, instituciones y tradiciones sociales y culturales de los pueblos, comunidades y personas indígenas".

A través de la remisión del artículo $5^{\circ}$ inciso segundo de la Constitución, se ha entendido que los derechos reconocidos en el Convenio № 169 de la

\footnotetext{
15 Aytwin et al. (2013), p. 295.

${ }^{16}$ La posibilidad de captura subsiste al precisar el inciso segundo del artículo 85 del Reglamento del SEIA que "la consulta [a los indígenas] deberá efectuarse con la finalidad de llegar a un acuerdo o lograr el consentimiento". Frente a este riesgo, FAUNDES (2013) recuerda que la Corte Suprema, en sentencia rol No 4078-2010, de 14 de octubre de 2010, ha prevenido que "este diálogo ha de tenerse de buena fe", entendiendo por ello la intención "de abandonar posiciones propias con el propósito de lograr otras que surjan consensuadas", lo que "necesariamente debe hacerse a través de organismos representativos y libremente".

17 En este sentido, la Corte Interamericana de Derechos Humanos ha señalado que "La estrecha relación de las comunidades indígenas con su territorio tiene -en general- un componente esencial de identificación cultural basado en sus propias cosmovisiones (...)". Corte Interamericana de Derechos Humanos, C No 245, de 27 de junio de 2012, párrafo 159.
} 
OIT pasan a formar parte del bloque de constitucionalidad, por lo cual son autoejecutables. Así lo resolvió la Corte de Apelaciones de Temuco en un fallo confirmado por la Corte Suprema ${ }^{18}$, sobre corte ilegal de árboles en menokos, en que se justificó un significado amplio del concepto de medioambiente incorporando la variable cultural para estimar que se violaba el artículo 19 № 8 de la Constitución, haciendo aplicable normas del Convenio № 169 de la OIT al establecer el deber de los Estados de adoptar las medidas necesarias para salvaguardar las culturas y medioambiente de los pueblos. Así mismo lo estimó la Corte Suprema al acoger un recurso de protección en el cual se declara ilegal el acto administrativo de la Corema de Los Lagos que calificó favorablemente la Declaración de Impacto Ambiental "Parque Eólico de Chiloé", señalando que se debe aplicar la consulta en los términos que dispone el Convenio No $169 .{ }^{19}$

Sin embargo, la protección del concepto de territorio indígena y la consulta obligatoria por la vía de la autoejecución del Convenio $N^{\circ} 169$ ha enfrentado una serie de dificultades a nivel interno. Hay autores que estiman que el Convenio № 169 no es autoejecutable por el solo mérito del tratado, lo que implica que el Estado debe dictar nueva legislación o adecuar la existente ${ }^{20}$. En este sentido, la jurisprudencia constitucional tampoco es pacífica, ya que el Tribunal Constitucional ha expresado que, si bien el Convenio no es inconstitucional, las normas del tratado en cuestión son programáticas y, por lo tanto, no son suficientes para hacerse efectivas sin las pertinentes modificaciones normativas para su establecimiento adecuado. ${ }^{21}$

A nivel interno, el D.S. No 66 de 2013, del Ministerio de Desarrollo Social, contiene el Reglamento sobre Consulta y Participación Indígena, el que ha sido criticado por ser ambiguo en la determinación de la susceptibilidad de afectación directa sobre los indígenas que justifica el deber de consulta y restringir -por esa vía-su aplicación frente a proyectos de explotación de recursos naturales ${ }^{22}$. Asimismo, se lo ha criticado ya que parte de las organizaciones indígenas se restaron del proceso de elaboración del Reglamento por estimar que su contenido

\footnotetext{
${ }^{18}$ Corte Suprema, rol № 7287-09, de 30 de noviembre de 2009, que confirmó la sentencia de fecha 16 de septiembre de 2009 de la Corte de Apelaciones de Temuco.

${ }^{19}$ Corte Suprema, rol № 10090-011, de 22 de marzo de 2012, considerando noveno.

${ }^{20}$ Fernández et al. (2012).

${ }^{21}$ Tribunal Constitucional, rol No 1988-011, de 24 de junio de 2011. Tribunal Constitucional, rol № 2387-013, de 23 de enero de 2013. Tribunal Constitucional, rol № 2523-013, de 30 de septiembre de 2013.

22 LÓPEZ Y MOHR (2014).
} 
no estaba de acuerdo al estándar internaciona ${ }^{23}$ y por establecer su observancia facultativa por parte de los organismos autónomos del Estado (art. $4^{\circ}$ ).

No obstante lo anterior, si bien el principio de consulta indígena abre la "posibilidad real de influir en la implementación ubicación y desarrollo de un proyecto", como lo ha señalado la Corte Suprema, ${ }^{24}$ y jugar un papel decisivo en la prevención y resolución de $\operatorname{conflictos}^{25}$ sobre los recursos naturales, ella está limitada a buscar el acuerdo con las comunidades indígenas afectadas, por lo que constituye una forma de recabar opinión que, según cierta jurisprudencia del Tribunal Constitucional, puede no resultar "vinculante, ni afectará las atribuciones privativas de las autoridades que la Constitución Política de la República establece" ${ }^{26}$ Por otra parte, la consulta no permite anticipar ex ante zonas de protección que no estén sujetas a una contingencia de oportunidad que hagan sensible la consulta ante distintos mecanismos de presión, por ejemplo, ante un proyecto de explotación. En este sentido, la consulta no otorga per se plena seguridad jurídica a los intereses de los indígenas.

Como consecuencia de lo anterior, conviene reflexionar en torno al modelo canadiense, en que los conflictos sobre el territorio se han resuelto a través de la gestión compartida de los recursos naturales con los indígenas. En definitiva, se trata de garantizar la capacidad de decisión vinculante del pueblo indígena en el proceso de otorgamiento de autorizaciones de proyectos de inversión. A pesar del resultado exitoso ${ }^{27}$, existen serias dificultades para darle viabilidad a nivel nacional. Por una parte, el Tribunal Constitucional ha advertido que no pueden afectarse las atribuciones privativas de las autoridades que la Constitución establece si no es por ley orgánica constitucional, y, por otra, ello implicaría el ejercicio de la soberanía por parte de los indígenas, lo que contraviene el artículo $5^{\circ}$ de la Constitución, con la consecuente necesidad de modificar la carta fundamental ${ }^{28}$.

\section{Hacia una propuesta normativa que resguarde el derecho cultural de los mapuches a su territorio: Los instrumentos de planificación territorial como alternativa}

Las dificultades señaladas precedentemente obligan a profundizar, entonces, en el régimen administrativo de explotación de los recursos naturales, para

\footnotetext{
23 Meza et al. (2014).

24 Corte Suprema, rol № 10090-011, de 22 de marzo de 2013.

25 ОІт (2011).

26 Tribunal Constitucional, rol No 1050-08, de 3 de marzo de 2008.

27 IMAI (2013).

28 Tribunal Constitucional, rol № 1050-08, de 3 de marzo de 2008, considerando decimotercero.
} 
proponer una propuesta normativa que resguarde el derecho cultural de los mapuches a su territorio.

Los recursos naturales -a excepción de los bosques- están concebidos jurídicamente como bienes de dominio público que, si bien son inapropiables, pueden transferirse a los privados a través del derecho exclusivo de uso y explotación que constituye el régimen de concesiones. Ahora bien, los bienes de dominio público están caracterizados en el artículo 19 № 23 de la Constitución como bienes cuyos usos "deban pertenecer a la Nación toda". Es decir, su nota característica es su destinación al interés público ${ }^{29}$. Destinación que debe ser apreciada en virtud del principio de supremacía constitucional (art. $6^{\circ}$ de la Constitución Política de la República) por la autoridad respectiva al momento de otorgar una concesión, en armonía con el artículo $1^{\circ}$ inciso tercero del texto fundamental, que consagra un principio de Estado social de derecho, al señalar que "el Estado está al servicio de la persona humana y su finalidad es promover el bien común, para lo cual debe contribuir a crear las condiciones que permitan a todos y a cada uno de los integrantes de la comunidad nacional su mayor realización espiritual y material posible". Esta promoción armónica de todos los sectores de la nación se traduce, entre otras cosas, en el deber de resguardar y promover el interés indígena al entregar una concesión. Incluso la misma Ley Indígena en su título II, que se refiere al "Reconocimiento" y "Protección" de las tierras indígenas, señala en su artículo 13 que esta protección es necesaria por "exigirlo el interés nacional".

En consecuencia, la nota distintiva es la discrecionalidad de la Administración para apreciar la mejor satisfacción del interés público al momento de otorgar o no una concesión. Dado que el derecho del particular a usar y explotar sólo nace en ese momento, nada impide que la Administración se abstenga de otorgar una concesión en consideración de la protección del interés de los indígenas sobre su territorio. En el caso de las concesiones marítimas, tanto los artículos $5^{\circ}$ como $8^{\circ}$ del D.S. № 2 de 2006, del Ministerio de Defensa, dan sustento positivo a esta interpretación, al señalar que la Subsecretaría de Fuerzas Armadas "podrá" otorgar o denegar una solicitud cuando cause perjuicio a terceros; para ello, los artículos 29 y 30 les otorga atribuciones a la Subsecretaría precitada y a Directemar para "evaluar los mejores usos para el área".

Sin embargo, una solución de este tipo está sujeta a ciertas dificultades. En lo que se refiere a la constitución de derechos de aprovechamiento sobre las aguas, la discrecionalidad de la administración para constituir la concesión esta

29 Montt (2002). 
coaptada normativamente ${ }^{30}$, a pesar de que excepcionalmente se puede denegar la concesión en razón del interés nacional por decreto del presidente de la República (art. 147 bis Código Aguas). Por su parte, respecto de los bosques, el derecho para explotar es un atributo del dominio del propietario del terreno pues se trata de un bien inmueble por adherencia (art. 568 Código Civil), que no requiere concesión. Una tercera dificultad radica en que, al concesionar, la autoridad puede considerar que existe otro concepto de interés público dominante.

En virtud de lo anterior, estimamos que es posible avanzar a través de los actuales instrumentos de planificación territorial en la protección del territorio cultural indígena, que son además los mecanismos adecuados para gestionar el territorio y precaver ex ante los conflictos, estableciendo zonas de protección del territorio simbólico indígena.

En efecto, el artículo 67 de la Ley de Pesca (modificada por la Ley № 20.434, de 2010) establece que la planificación territorial del borde costero es "vinculante al momento de otorgar una concesión de acuicultura". De la misma forma, el D.S. N 2 de 2005, del Ministerio de Defensa, establece que el otorgamiento de concesiones sobre terrenos de playa, playas, rocas, porciones de agua, fondo de mar, dentro y fuera de las bahías del mar, como de los ríos y lagos navegables por buques de más de 100 toneladas debe hacerse de acuerdo a la zonificación del borde costero (art. 25). Por su parte, al municipio le corresponde otorgar estas concesiones cuando se trata de lagos y ríos navegables por buques de menos de 100 toneladas, así como sobre cauces o álveos (art. 5º de la Ley Orgánica de Municipalidades). Al respecto, cuando se trata de áreas urbanas, los bienes nacionales de uso público locales y que correspondan a terrenos de playa o riberas de mar, de ríos y de lagos navegables, se usarán en concordancia con lo dispuesto en el Plan Regulador Comunal y su Ordenanza Local (art. 64 Ley General de Urbanismo y Construcciones o LGUC).

Respecto de las aguas terrestres, la Dirección General de Aguas concede su aprovechamiento, por lo que no tiene competencia sobre los suelos por los cuales discurren. No obstante, las obras de infraestructura de captación y distribución están sujetas a la Ley General de Urbanismo y Construcciones como a la Ordenanza General de Urbanismo y Construcciones (Oguc) en el art. 2.1.29 y, por esa vía, a la planificación territorial.

En lo que se refiere al área rural (donde se encuentra la mayor parte de los recursos naturales que son objeto de conflicto), la dictación en febrero de 2018 de la Ley $N^{\circ}$ 21.074, que modifica el artículo 17 letra a) de la Ley de Administración y Gobierno Regional, constituye un avance extraordinario, ya que establece el carácter vinculante del Plan Regional de Ordenamiento Territorial (PROT) y

30 YÁÑEZ et al. (2008). 
dispone que, en áreas que no estén sometidas a planificación urbanística, se llevara a cabo una macrozonificación del territorio de la región, a fin de lograr un desarrollo sustentable, estableciendo condiciones para la localización de infraestructuras y actividades productivas junto con áreas para su localización preferente. El incumplimiento de estas condiciones "provocará la caducidad de las autorizaciones respectivas", caducidad de las "autorizaciones" que -en sentido amplio- alcanzaría tanto a los planes de manejo forestal y al otorgamiento de concesiones como a las autorizaciones sectoriales para la explotación de un recurso natural. La ley establece, además, que será de cumplimiento obligatorio para los "servicios públicos que operen en la región (...)". En este sentido, constituye un avance frente al carácter puramente programático de Plan Regional de Desarrollo Urbano y del Plan Regulador Intercomunal, que, si bien puede regular el suelo rural, es preferentemente urbano y aborda la zona rural de forma puramente incidental ${ }^{31}$.

Las ventajas radican en que -al incorporarse al bloque de legalidad previsto en el artículo 29 de la Ley General de Urbanismo y Construcciones- los Instrumentos de Planificación Territorial deben ser observados por todos los habitantes de la República a la vez que imponen un principio de coordinación forzosa con los otros órganos del Estado, frente al principio de coordinación voluntaria de los órganos del Estado establecido en el art. $4^{\circ}$ de la Ley Orgánica Constitucional de Bases General de Administración del Estado, que ha privilegiado una visión unilateral en que la legislación sectorial de los bienes públicos con incidencia territorial que son asumidos como externos al ordenamiento espacial ${ }^{32}$. Asimismo, los Instrumentos de Planificación Territorial pueden limitar derechos constitucionales al respetar el principio de reserva legal. Por otra parte, disminuyen los costos de transacción del mercado al visibilizar anticipadamente los $\operatorname{conflictos}^{33}$, a la vez que dan seguridad jurídica a los intereses indígenas. Tiene, asimismo, la ventaja frente al SEIA de no ser un mecanismo casuístico para prevenir daño ambiental. Además, esta propuesta normativa tiene la ventaja de contemplar una forma privilegiada de participación con la entrada en vigencia del reglamento para la EAE (Evaluación Ambiental Estratégica).

\section{Consideraciones finales}

Si bien estimamos que es posible avanzar en precaver conflictos y lograr una explotación sustentable de los recursos naturales de zonas con asentamientos

31 Cordero (2007).

32 Cordero (2007).

33 POSNer (1973). 
mapuches a través de la protección del derecho al territorio de los indígenas por la vía de Instrumentos de Planificación Territorial, una posición de este tipo ostenta una serie de dificultades que deben ser esclarecidas. Desde ya, al revisar la Ordenanza General de Urbanismo y Construcciones no se norman los tipos de zonas de protección de asentamiento indígenas. Un ejemplo claro es la comunidad Coliñir en Isla Teja Valdivia, que demanda la protección de un centro ceremonial que no corresponde a los tipos de zona de protección definidas por la OGUC. AI mismo tiempo, no queda claro si el PROT -dictado a través de acto administrativo- tiene valor legal, al señalar la ley escuetamente que es "vinculante" (art. 17 de la Ley No 21.074). Con relación a la zonificación del borde costero, no se sistematiza su relación con los demás instrumentos de planificación ni con el PROT, a la vez que no está incorporada al bloque de legalidad del artículo 29 de la LGU. Además, falta darle aplicabilidad al PROT por medio de un reglamento, a la vez que falta sistematizar los tipos de actividades, equipamiento y tipos de usos de suelo admisibles en zona rural, que son enteramente distintos que en zona urbana. Por otra parte, falta determinar la necesidad de un plano de detalle para zonas rurales, a la vez que las normas que se refieren a uso rural en la OGUC son demasiado escasas. Asimismo, se debe revisar el artículo 2.1.29 de la OGUC, que establece un estatuto preferente para la legislación sectorial de infraestructura y que restringe la planificación territorial para este tipo de usos. Por último, y no menos importante, se debe mencionar el hecho de que la viabilidad del PROT depende de un reglamento de la Ley $N^{\circ} 21.074$, que no ha sido dictado. Además, sus efectos estarán subordinados a la Política Nacional de Ordenamiento Territorial (PNOT), la que aún no ha sido dictada. Por último, la función protectora del PROT estará vinculada directamente a la capacidad de lograr una participación adecuada de los mapuches en el levantamiento de las zonas culturales que deben ser objeto de protección. En síntesis, un esfuerzo de sistematización y desarrollo normativo está pendiente. No obstante, con la elección de gobernadores regionales en el año 2020, se puede anticipar un previsible impulso a este tipo de instrumentos.

\section{BiBLIOGRAFÍA CITADA}

ARENAS, Federico (2000): “El ordenamiento territorial: Un nuevo tema para la planificación", en: Arenas, Federico, y Cáceres, Gonzalo, Ordenamiento del territorio en Chile. Desafíos y urgencias para el tercer milenio (Santiago, Ediciones Universidad Católica de Chile), pp. 201-214.

AytwIN, José (1995): "Estudio sobre tierras indígenas de La Araucanía": Antecedentes histórico-legislativos (1850-1920) (Temuco, Instituto de Estudios Indígenas, Universidad de La Frontera). 
(2000): "Materializaciones y conflictos": Aplicación de la Ley Indígena en el Territorio Mapuche (1994-1997) (Temuco, Instituto de Estudios Indígenas, Universidad de La Frontera).

(2009): "El derecho internacional de los derechos humanos y los pueblos indígenas", en: Aylwin et al., Las implicancias de la ratificación del Convenio NNo 169 de la OIT en Chile (Santiago: Heinrich Böll Stiftung), pp. 9-20.

Aytwin, José; MeZA-Lopehandía, Matías, y YáÑez, Nancy (2013): Los pueblos indígenas y el derecho (Santiago, LOM Ediciones).

Banco Mundial (2011): "Chile: Diagnóstico de la gestión de los recursos hídri-

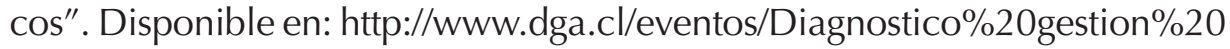
de\%20recursos\%20hidricos\%20en\%20Chile_Banco\%20Mundial.pdf [visitado el 9 de junio de 2019].

BenGoA, José (2000): Historia del pueblo mapuche (Siglo XIX y XX) (Santiago, LOM Ediciones).

Carmona, Cristóbal (2013): "Tomando los derechos colectivos en serio: El derecho a consulta previa del Convenio 169 de la OIT y las instituciones representativas de los pueblos indígenas", en: Revista lus et Praxis (año 19, $N^{\circ} 2$ ), pp. 301-334.

Cordero Quinzacara, Eduardo (2007): "El derecho urbanístico, los instrumentos de planificación territorial y el régimen jurídico de los bienes públicos", en: Revista de Derecho de la Pontificia Universidad Católica de Valparaíso (Vol. XXIX), pp. 269-298.

(2011): "Ordenamiento territorial, justicia ambiental y zonas costeras", en: Revista de Derecho de la Pontificia Universidad Católica de Valparaíso (Vol. XXXVI), pp. 209-249.

Faundes PeÑafiel, Juan Jorge (2013): "La jurisprudencia, su impacto y debates en torno a la aplicación en Chile del Convenio № 169 de la OIT y el deber de consulta", en: Revista de Derecho de la Universidad de Concepción ( $\mathrm{N}^{\circ} \mathrm{s} .233-$ 234, año LXXXI), pp. 195-230.

Fernández, Margarita, y Salinas, Javier (2012): Defensa de los derechos territoriales en América Latina (Santiago, RIL Editores).

Fraser, Nancy, Y HONNETH, Axel (2006): ¿ Redistribución o reconocimiento? Un debate político-filosófico (Madrid, Morata).

GISSI, Nicolás; IBACACHE, Daniela; PARdo, Bernardo, y ÑANCUCheO, María Cristina (2017): "El Estado chileno, los lafkenche y la Ley № 20.249: ¿Indigenismo o política del reconocimiento?", en: Revista Austral de Ciencias Sociales (№ 32), pp. 5-21. 
HeRVÉ, Dominique (2015): Justicia ambiental y recursos naturales (Valparaíso, Ediciones Universitarias de Valparaíso).

Honneth, Axel (1997): La lucha por el reconocimiento. Por una gramática moral de los conflictos (Barcelona, Crítica).

IMAI, Shin (2013): "Indigenous Peoples in Canada: Self Determination and Rights to Land", en: Comparative Research in Law \& Political Economy ( $\left.\mathrm{N}^{\circ} 2\right)$.

Liberona, Flavia (2011): Servicio de Biodiversidad y Áreas Protegidas. Disponible en: http:// https://www.terram.cl/descargar/naturaleza/biodiversidad/ ppt_-_presentacion_power_point/PPT-Servicio-de-Biodiversidad-y-AreasProtegidas-Diciembre-2011.pdf [visitado el 9 de junio de 2019].

LÓPEZ VyHMEISTER, Ricardo, y MoHR, Tatiana (2014): "Susceptibilidad de afectación directa en la consulta previa del Convenio 169. Análisis de normas previstas de su trato en la jurisprudencia: ¿Una cuestión de derecho?", en: Revista de Derecho (Vol. XXVII, No 1), pp. 105-126.

Meza-Lopehandía, Matías; Yáñez, Nancy, y Siıva, Hernando (2014): "El derecho a la consulta y su incorporación al sistema jurídico chileno", en: Acevedo, Paulina, El derecho a la consulta de los pueblos indígenas: Análisis del derecho nacional, internacional y comparado (Santiago de Chile, IWGIA Observatorio Ciudadano), pp. 19-46.

Montt Oyarzún, Santiago (2001): El dominio público. Estudio de su régimen especial de protección y utilización (Santiago, ConoSur).

OIT (2011): Convenio sobre pueblos indígenas y tribales (CEACR). Observación general sobre la obligación de consulta, de 16 de febrero de 2011 (ILC.100/ III/1 $\left.{ }^{\mathrm{a}}\right)$.

ONU (2009): Informe del Relator Especial sobre la situación de los derechos humanos y las libertades fundamentales de los indígenas, James Anaya. La situación de los pueblos indígenas en Chile: Seguimiento a las recomendaciones hechas por el Relator Especial anterior, de 5 de octubre de 2009 (A/HRC/12/34/Add.6).

PINTO, Julio (2000): De la inclusión a la exclusión. La formación del Estado, la nación y el pueblo mapuche (Santiago, Instituto de Estudios Avanzados, Universidad de Santiago).

POsner, Richard (1973): Economic Analysis of Law (Boston, Little, Brown and Company).

RUBILAR, Gabriela, y RolDAN, Andrés (2014): “Áreas de desarrollo indígena: Estudio de caso del ADI puel nahuelbuta, como estrategia de las políticas públicas en el mundo mapuche", en: Universum (Vol. 29, № 2), pp. 253-276. 
SAlAZAR, Gabriel (1985): Labradores, peones y proletarios (Santiago, Ediciones Sur).

VILLEGAS, Myrna (2008): "Informe final del proyecto Derecho penal del enemigo y la criminalización de las demandas mapuche, Universidad Central de Chile, 31 de octubre de 2008". Disponible en: http://www.cienciaspenales. net/files/2016/07/2derecho-penal-del-enemigo-y-criminalizacion-de-las demandas-mapuche.pdf [visitado el 9 de junio de 2019].

YÁÑez, Nancy, y Molina, Raúl (2008): La gran minería y los derechos indígenas en el norte de Chile (Santiago, LOM Ediciones). (2011): Las aguas indígenas en Chile. Observatorio ciudadano (Santiago, LOM Ediciones). 